in which connected people prioritize shared ideology and politics over facts and evidence.

Twain's own ideology and politics have proved notoriously difficult to pin down. He is regularly claimed as a hero and figurehead by both liberals and conservatives, which makes him unusual - because, as an analysis shows this week (F. Shi et al. Nature Hum. Behav. 1, 0079; 2017), common ground between the two positions seems increasingly scarce.

If you live in the United States and buy books online, then this analysis could be about you. Especially if you bought Barack Obama's Dreams from My Father (Times, 1995) or Mitt Romney's No Apology (St Martin's, 2010) from Amazon or Barnes and Noble. If you did, then you may have been labelled as a liberal or conservative, your other book purchases may have been checked, sifted and classified, and the results could be buried in the massive data set described in Nature Human Behaviour. (Don't worry if you did - the results are anonymous.)

Taking advantage of the 'customers who bought this item also bought' feature of online commerce, the researchers constructed a co-purchase network of political books and science books. And they found a clear division, which they label "partisan differences in the consumption of science".

Both groups bought science books - more than 400,000 between them. But it was relatively unusual to find books that appealed to both liberals and conservatives. Members of each group - and their good friends - had different ideas about what made a good book. Buyers of "blue books" (the liberals) tended to pick from basic science topics, including physics, astronomy and zoology. "Red" customers preferred books that discussed applied and commercial science, such as medicine, criminology and geophysics. And whereas liberal choices tended to reflect mainstream thinking, "red books" tended to be co-purchased with a narrower subset of science books on the fringes of each subject.

It's not just purchases of science books that can be analysed in this way. The researchers have a website (lifestyle-politics.com) on which they use information from Twitter followers of politicians to build similar profiles of how liberals or conservatives tend to group around certain reading material isjudged by some as denoting an alert or sleepy conscience."
"Choice of comedians, actors, makes of car, airlines and other everyday preferences. Sport, for example, sees liberals associate with brands that are connected to outdoor adventurous pursuits such as hiking and mountaineering, whereas the conservative right is more at home with companies that make golf clubs.

The results might seem obvious, but such studies come with a couple of major advantages. The first is the massive quantity of available online data, which - subject to proper safeguards - offers rich potential for social scientists and others. The second, as the researchers point out, is that the data on tastes, preferences and behaviour are probably more useful and reliable than surveys: "Surveys measure what researchers think is important, not what respondents care about." And with people's choices of reading material still judged by some as denoting an alert or sleepy conscience, surveys are vulnerable to people being reluctant to reveal tastes that could be considered politically incorrect. Books purchased online, as the study points out, come "cloaked in cardboard". Social groups, especially on the Internet, are going the same way - and discovering a way to peek inside and find common ground is a defining challenge of the age.

\section{Not English}

\section{Brexit poses a linguistic problem and forces decisions on agency locations.}

$\mathrm{N}$ ow that the Brexit process is officially under way, officials must decide where to rehouse the European Medicines Agency (EMA). Currently in London, the EMA assesses new medicines for suitability to enter the European market.

The regulator will need to move when the United Kingdom formally exits the European Union, which sets the rules and assessments that the agency enforces.

The relocation decision will be made by the European Council, and more than a dozen nations have expressed an interest in becoming the new host. The timescale of the process is uncertain, but at least one of the candidate nations - Malta - has an interest in a final call being made sooner rather than later because it holds the presidency of the European Council for the next three months.

There is more at stake than the prestige of being the headquarters of a major European institution. Local economies gain too. The EMA brings with it some 900 staff and holds an average of 10 meetings a week, which it claims draw 65,000 visitors a year, all of whom need somewhere to sleep and eat.

Malta - a tiny island in the Mediterranean Sea - knows that it's a rank outsider in the bidding process. But, as officials of the Malta Medicines Agency pointed out at a meeting last September, it does have a few things going for it. One is the weather. Another, according to its own analysis, is reduced commuting time for employees. (How far away can they live on an island of barely 300 square kilometres?) More intriguingly, Malta points out that another benefit is that one of its official languages is English - the lingua franca of science, law and business in the EU.

By a curious quirk of paperwork, when the United Kingdom does leave the EU, the most widely spoken language across the bloc - English - will no longer be a nominated official language. Under EU rules, every member state is allowed to bring just one of its recognized national languages into the EU system. This guarantees, for example, translations of documents and decisions.

Under the existing arrangement, the United Kingdom currently nominates English, which leaves Ireland and Malta (the only other member states to have English as a formal national language) free to have Gaelic and Maltese as their choices. (Ireland has also offered to host the EMA.) Once the United Kingdom leaves, it takes with it the formal nomination for the EU to include English in its list of official voices.

Various EU officials have already made it clear that the English language will not be allowed to exit the EU along with its main speakers on the continent - chaos would surely follow if, for example, the English-speaking EMA was expected to work with documents in every language but English. But the political mechanism to secure a future for English - like much associated with Brexit — is contested and unclear.

As international researchers point out in a paper in European Economic Review, there are three possible routes (V. Ginsburgh et al. Eur. Econ. Rev. 93, 139-151; 2017). The first is that the European Council votes to keep English even without an official nomination from a member state. This would require the approval of Germany and France, and the latter, especially, might be especially unwilling to offer it. Many French scholars still smart at English's rise to dominance in intellectual fields.

Another option is special permission for Ireland or Malta to nominate a second official language. But that would build pressure from other countries and regions to also have additional languages accepted. More than three million people in Spain speak Galician, and more than six million speak Catalan - greater than the populations of Ireland and Malta combined.

The simplest solution might simply be to ask Ireland or Malta to switch their official nomination to English. Local opposition in both cases could make that a hard sell for their respective governments. Now what could the EU - looking for a home for the EMA — possibly offer in return? 